\title{
Attacking the Basics: What Fuels a Wound
}

\section{INTRODUCTION}

Simply put, three major components control the existence and outcome of a wound:

1. The wound environment, which ultimately is the patient.

2. The healthcare providers and the caretakers.

3. The type of dressing.

Each of these components has both intrinsic and extrinsic factors that play a role in whether an acceptable or positive outcome is achieved. The ability to change these factors ultimately influences the outcome, as it pertains to the realistic time frame and ability to heal a wound. As Confucius said, "By nature, men are nearly alike; by practice, they get to be wide apart." The same is true of wounds; no two are exactly alike. This chapter will help you understand what fuels a wound and how to start your approach in wound care and wound healing.

In this chapter, you will learn:

1. The three major components that contribute to optimal wound healing and the extrinsic and intrinsic factors that influence them. 
2. How the wound care provider works in conjunction with other specialists, staff, and family members to provide and manage personalized wound care plans and to educate and empower novice staff, patients, and caretakers.

\section{MAJOR COMPONENT 1: THE PATIENT AND THE PHYSIOLOGIC ENVIRONMENT}

To understand what fuels a wound, the healthcare provider must understand the wound from the inside out. This knowledge will come from knowing what intrinsic and extrinsic factors are driving the wound. Obtaining a thorough and accurate history and assessment of the patient is the initial step. Take the time to know your patient.

Extrinsic patient factors to note:

- For the history

- Lifestyle factors such as smoking and use of alcohol

- Socioeconomic status

- For assessment

- Moisture

- Mechanical stress such as compression, tension, shear, or contractures

- Chemical stress such as what occurs when tissue is damaged or inflamed

- Infection

Intrinsic patient factors to note:

- Age

- Comorbidities

- Diabetes

- Peripheral vascular disease

- Chronic cardiopulmonary disease

- Cardiovascular disease

- Obesity

- Autoimmune disorders

- Nutritional status

- Overall health and well-being

\section{LIFESTYLE FACTORS}

Nicotine is a potent vasoconstrictor; it reduces the flow of vital nutrients and oxygen to tissue. Nicotine also increases platelet adhesiveness, resulting in microvascular occlusion, and reduces proliferation 
of red blood cells. Both carbon monoxide and cyanide inhibit oxygen transport to cells and interfere with cellular metabolism.

Excessive alcohol intake impairs wound healing by compromising the immune system, therefore increasing the likelihood of infections, and by increasing the risk of bleeding. People who drink alcohol in excess are concomitantly malnourished.

Patients with a wound of any nature must be counseled on the importance of smoking cessation and limiting alcohol intake. Incorporate assistive aids and resources into the patients' plan of care to facilitate these lifestyle modifications.

\section{MOISTURE}

Maceration caused by incontinence, sweating, or excess exudate from a wound bed all contribute to the breakdown of tissue. Consider the patient's ability to manage continence and intervene as warranted, especially for patients with mobility and sensory limitations.

Interventions to manage incontinence:

- Incontinence briefs

- Indwelling urinary catheters

- Condom catheters for men

- Purewick urine collection systems for women

- Fecal diversion with colostomies

Be diligent in managing both urinary and fecal incontinence and protect the incontinent patient's skin from prolonged contact with urine and feces with barrier products.

Barrier products:

- Calmoseptine

- Petroleum jelly

- Zinc oxide

Ensure the wound bed is free of excessive moisture, particularly by managing exudate with the appropriate type of dressing. Selecting correct dressings is discussed in detail in Chapter 9.

\section{MECHANICAL STRESS}

Tissue ischemia and eventual breakdown occur when a patient is immobile and pressure is exerted over bony prominences. Tissue damage can occur within 15 minutes of diminished blood flow. The forces of shearing and friction occur when the tissues underneath 
the skin are forced to move, such as when pulling instead of lifting a patient when the patient is lying down or sitting. Extremity contractures also cause mechanical stress by causing tissue ischemia.

Breakdown due to mechanical stress can best be prevented by frequent and diligent repositioning, by use of pressure-relieving devices, and by placing pillows between pressure areas such as the knees.

Pressure-relieving devices:

- Low-air-loss mattresses

- Heel and elbow protectors

- Prevalon boots

- Rojo cushions

\section{CHEMICAL STRESS}

If used in excess, common over-the-counter antiseptics and cleaning agents such as iodine, hydrogen peroxide, and rubbing alcohol can damage healthy cells. While they may reduce the bacterial load on the surface of a wound, they have no real effect below the skin's surface. Most wounds can be cleaned with simple soap and water. However, a number of wound cleaning solutions are available from companies that specialize in wound products that are not harmful to healing wounds.

\section{INFECTIONS AND BIOBURDENS}

Two of the most important components influencing wound healing are infection and bioburden. An infection occurs when pathogens colonize to the point of invading the host tissue. Pathogens can originate from several environmental sources that harbor bacteria, viruses, and fungus. Skin, in a healthy state, protects the body from invasion of pathogens through its stratum corneum layer. Additional body defenses against the invasion of pathogens include secretions from sebaceous glands and the body's immune system. Some pathogens are part of the body's natural flora and become harmful only after invading the tissue. These opportunistic pathogens are so named because they attack the body's defenses when an opportunity presents itself, such as during surgery, in the event of trauma, or through an existing wound. Bioburden is the number of contaminating pathogens on the surface of a wound.

Contamination is the presence of pathogens on the surface of the skin or a wound. Colonization occurs when contaminants multiply significantly and the body's immune system is overwhelmed. Signs of inflammation become apparent: redness, heat, and/or drainage. 


\section{BIOFILMS}

A biofilm is the extracellular matrix structure that attaches itself to a wound's surface tissue and protects pathogens from the host's defenses. Literature suggests that $60 \%$ to $90 \%$ of chronic wounds contain biofilm-forming bacteria.

A biofilm structure attaches itself firmly to the surrounding surface of the wound and must be scrubbed off; simply spritzing wound cleanser or pouring sterile water on the wound is not effective. Chronic wound biofilms tend to be highly resistant to antimicrobial agents.

Common biofilm-forming bacteria:

- Staphylococcus aureus (staph)

- Pseudomonas aeruginosa

- Beta-haemolytic streptococci (Strep)

- Enterococcus

- Klebsiella pneumoniae

- Acinetobacter

- Enterobacter

- Candida (yeast)

Factors that lead from wound contamination to biofilm to infection include:

- Pathogens resistant to antibiotic therapy

- The type and variety of pathogens

- The interaction of different bacterial species with each other

- The host's immune system response

Some of the most recent alternative treatments developed to target biofilms include:

- Negative pressure wound therapy (a mainstay of wound care)

- Blue light therapy

- Nano-antimicrobial agents embedded or coated onto dressings and drains

- Silver, copper, and zinc

- Modulation of $\mathrm{pH}$ with agents

- Acetic acid $1 \%$ or $5 \%$, ascorbic acid, Medihoney

- Medical maggots

- Hyperbaric oxygen therapy

- Surfactant-based products

- Plurogel, Aquacel Ag, Hydrogel, and Silvasorb gel

- Probiotics 


\section{Fast Facts}

\section{Wound Agents}

Bactericidal: An agent that destroys bacteria.

Bacteriostatic: An agent that can prevent new bacteria from growing or multiplying without destroying bacteria that are already present.

\section{DIAGNOSTIC FOLLOW-UP FOR CONFIRMING WOUND INFECTION}

Tissue biopsies, needle aspiration, and swab samples are the most common lab tests for diagnosing an infection. All chronic wounds are contaminated; therefore, diagnose actual wound infection based on clinical signs and from culture results. The goal is to establish a host-manageable bioburden.

\section{Tissue Biopsies}

Tissue biopsies can be completed utilizing a simple punch biopsy at the bedside or during surgical debridement. If osteomyelitis is suspected, it will be necessary for the provider to obtain a bone biopsy. While most bone biopsies are usually collected during surgical debridement, the procedure can be done at the bedside on select patients.

\section{Fast Facts}

\section{Clinical Indications for a Wound Culture}

- Systemic signs of infection, fever, leukocytosis (i.e., elevated white blood cell count)

- Sudden high blood glucose

- Increasing pain in a neuropathic extremity

- Lack of healing of a clean-appearing wound after 2 weeks

Signs and Symptoms of Infection at the Wound Site

- Pain or tenderness

- Excess drainage

- Red color

- Cutaneous warmth

- Unusual or foul odor

- Swelling or firmness (induration) 


\section{Needle Aspiration}

In needle aspiration, a thin needle is inserted directly into tissue; cells are aspirated and sent to pathology or microbiology for identification.

\section{Swab Samples}

A swab culture is taken by swabbing the surface of a wound or within the cavity of a wound. Exudate can also be collected by a swab culture. Swab cultures can easily be contaminated during the collection process, so be diligent with the collection process.

The Levine technique is believed to be most reflective of tissue bioburden. Rotate a swab over a $1 \mathrm{~cm}^{2}$ area with sufficient pressure to express fluid from within the wound tissue.

\section{TREATMENT OF INFECTIONS}

Treatment is targeted at reducing a wound's bacterial load and biofilm. The most effective treatment plan is combination therapy consisting of appropriate antibiotic selection based on culture sensitivities and dressing selection. See Tables 1.1 and 1.2.

Antimicrobial topical ointment and creams include:

- Bacitracin or Polysporin: Effective only against bacterial infections

- Bactroban 2\%: Effective primarily against Gram-positive bacteria Staph and Strep including methicillin-resistant S. aureus (MRSA)

- Silver sulfadiazine cream $1 \%$

- Sulfamylon cream $5 \%$

\section{SOCIOECONOMIC STATUS}

When establishing a wound care treatment plan, consider the patient's ability to afford the medications and products being prescribed and the ability to correctly carry out the wound care treatment. Many antibiotics, wound care products, and dressing supplies can be expensive and complicated to administer. Always determine if the patient's insurance provider will cover the products being prescribed. The treatment plan may have to be adjusted if the payor source will not cover certain products or if the patient is uninsured.

Provide extensive and ongoing education and demonstration to whomever will be performing the wound care treatments to ensure understanding and the ability to complete the task. Failure to address 
Table 1.1

\section{Antimicrobial Topical Solutions}

\section{Solution}

Dakin's solution

(sodium hypochlorite)

Puracyn Plus

(hypochlorous acid)

Silver nitrate $0.5 \%$ solution

Sulfamylon/mafenide acetate

\section{Effectiveness}

Broad-spectrum; effective against MRSA, VRE, other bacteria, viruses, mold, fungi, and yeast.

The same molecule that the body's neutrophils create as part of the immune system.

Provides broad-spectrum coverage.

Broad-spectrum bacteriostatic effective against many Gram-positive and Gramnegative bacteria.

Effective against systemic fungal infections and can be mixed with Amphotericin B.

MRSA, methicillin-resistant Staphylococcus aureus; VRE, vancomycin-resistant enterococci.

Table 1.2

\section{Antimicrobial Topical Dressings}

\begin{tabular}{ll} 
Dressing & Effectiveness \\
\hline Acticoat & Broad-spectrum effectiveness. \\
Exsalt & $\begin{array}{l}\text { Can be left intact for several days, } \\
\text { therefore, requires fewer dressing changes. } \\
\text { KerraContact Ag }\end{array}$ \\
$\begin{array}{l}\text { Mepilex Ag } \\
\text { Mepitel Ag }\end{array}$ & \\
$\begin{array}{l}\text { Promogran Prisma } \\
\text { Tritec Silver Nanocrystal based }\end{array}$ \\
$\begin{array}{l}\text { AMD kerlix (Polyhexamethylene } \\
\text { Biguanide) }\end{array}$ & Highly effective against most organisms. \\
\hline
\end{tabular}

both these factors will lead to a less than favorable outcome and noncompliance.

\section{AGE}

As we age, our skin becomes much drier and thinner as we lose secretory cells that help maintain moisture and elasticity. Teach patients and their care providers how to keep the skin well hydrated with a nonalcohol-based moisturizer. 


\section{COMORBIDITIES}

Many chronic health conditions such as diabetes, chronic kidney disease, cardiopulmonary disease, cardiovascular disease, cancer, and autoimmune-driven conditions can both cause a wound to develop and impede wound healing. It is critical that patients with a wound have regular appointments with their primary care provider with the goal of optimal chronic disease management in mind.

\section{Fast Facts}

- Uncontrolled diabetes can affect wound healing by damaging nerves resulting in lack of sensation, causing poor immune system response, creating a high-risk environment for wound infection, and causing impaired blood flow.

- Smoking affects wound healing by impairing tissue oxygenation and collagen deposition necessary for wound closure.

- Pain affects wound healing by causing vasoconstriction and immune system suppression.

\section{NUTRITION}

The role of nutrition in wound care must not be overlooked. Both macronutrients and micronutrients must be in balance to provide an optimal state for wound healing. See Table 1.3. It is estimated that caloric needs during wound healing are $30-40 \mathrm{kcal} / \mathrm{kg}$.

\begin{tabular}{ll}
\hline Macronutrients & Carbohydrates, fats, proteins, and fluids \\
Micronutrients & Amino acids, vitamins, and minerals \\
\hline
\end{tabular}

When assessing the patient with a wound, note if the patient has inadequate intake.

Causes of inadequate nutritional intake:

- Poor appetite

- Inability to feed oneself

- Overeating

- Impaired sense of taste or smell

- Difficulty swallowing

Physical assessment:

- Weight and weight loss or gain

- Body mass index 
Table 1.3

Laboratory Parameters

\begin{tabular}{lll} 
& Normal Ranges & Possible Indications \\
\hline Serum albumin & $3.4-5.4 \mathrm{~g} / \mathrm{dL}$ & $\begin{array}{l}\text { A lower level can indicate } \\
\text { malnutrition. }\end{array}$ \\
Serum prealbumin & $15-36 \mathrm{mg} / \mathrm{dL}$ & $\begin{array}{l}\text { A lower level can indicate } \\
\text { malnutrition. }\end{array}$ \\
$\begin{array}{l}\text { Retinol-binding } \\
\text { protein }\end{array}$ & $40-60 \mathrm{ug} / \mathrm{mL}$ & $\begin{array}{l}\text { A lower level can indicate } \\
\text { nutritional deficiencies. }\end{array}$ \\
Serum creatinine & $0.6-1.2 \mathrm{mg} / \mathrm{dL}$ for males & $\begin{array}{l}\text { A lower level indicates too } \\
\text { little creatine in muscle } \\
\text { tissue. }\end{array}$ \\
& $0.5-1.1 \mathrm{mg} / \mathrm{dL}$ for & A lower level can indicate \\
females & $\begin{array}{l}\text { liver disease or hemolytic } \\
\text { anemia. }\end{array}$ \\
Transferrin & $170-370 \mathrm{mg} / \mathrm{dL}$ &
\end{tabular}

- Loss of subcutaneous fat

- Edema

- Muscle wasting

- Fatigue

- Reduced grip strength

Fluid intake is another important factor to consider. The goal for the patient with a wound is $1 \mathrm{~mL} / \mathrm{kcal} /$ day but will need to be adjusted for insensible fluid losses and for patients with cardiac and renal disease.

Causes of insensible fluid loss:

- Fever

- Vomiting

- Diarrhea

- Diuresis

- Fistulae output

- Wound exudate

The patient's socioeconomic status should also be assessed since many people, particularly the elderly, have social and economic difficulties that put them at nutritional risk. Determine their access to and ability to afford food, ability to prepare food, and availability of resources.

The Mini Nutritional Assessment is a widely used tool to assess malnutrition. It incorporates food intake, weight loss patterns, mobility, and neuropsychiatric contributors to eating (see Exhibit 1.1). 
Diagnostic markers to assess nutritional status:

- Albumin

- Prealbumin

- Transferrin

- C-reactive protein

It is important to establish a nutritional plan as part of the overall wound care treatment plan (see Table 1.4). Some patients may need modified diets depending on the ability to chew and swallow while others may need feeding tubes. In addition to education regarding a balanced diet, incorporate supplemental micronutrients such as arginine, glutamine, and multivitamins. The anabolic steroid oxandrolone is an effective pharmacological agent to reduce protein catabolism in patients with burn injuries and complex wounds. The recommended dose is 5 to 10 $\mathrm{mg}$ BID. There are many protein supplements available in various forms such as powders, shakes, and bars that can be added to the patient's diet.

\section{MAJOR COMPONENT 2: THE HEALTHCARE PROVIDERS AND THE CARETAKERS}

For the sick, it is important to have the best.

Florence Nightingale

You will not likely know what patients you will care for each day or even what wounds they will have. What is your plan? What is your goal for your patients today?

The goal of wound care specialists is to raise the bar in wound care management. Considering current healthcare and economic issues, we need now more than ever to step up and define our position. Wound care teams have the potential to save hospitals money, improve patient outcomes, and raise the "novice-to-expert" bar related to wound care in every unit with a consultancy team approach. No matter the organization or healthcare facility, a wound care provider's responsibilities and roles are threefold-clinical expert, educator, and researcher:

\section{Clinical Expert: Directing Wound Management}

- Understands the healthcare system's group purchasing organization.

- Works with the facility's purchasing staff/formulary to develop state-of-the-art wound management formularies and shared costreduction strategy goals.

- Shares responsibility for development and implementation of wound and skin care policies, procedures, and guidelines. 


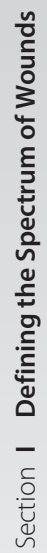
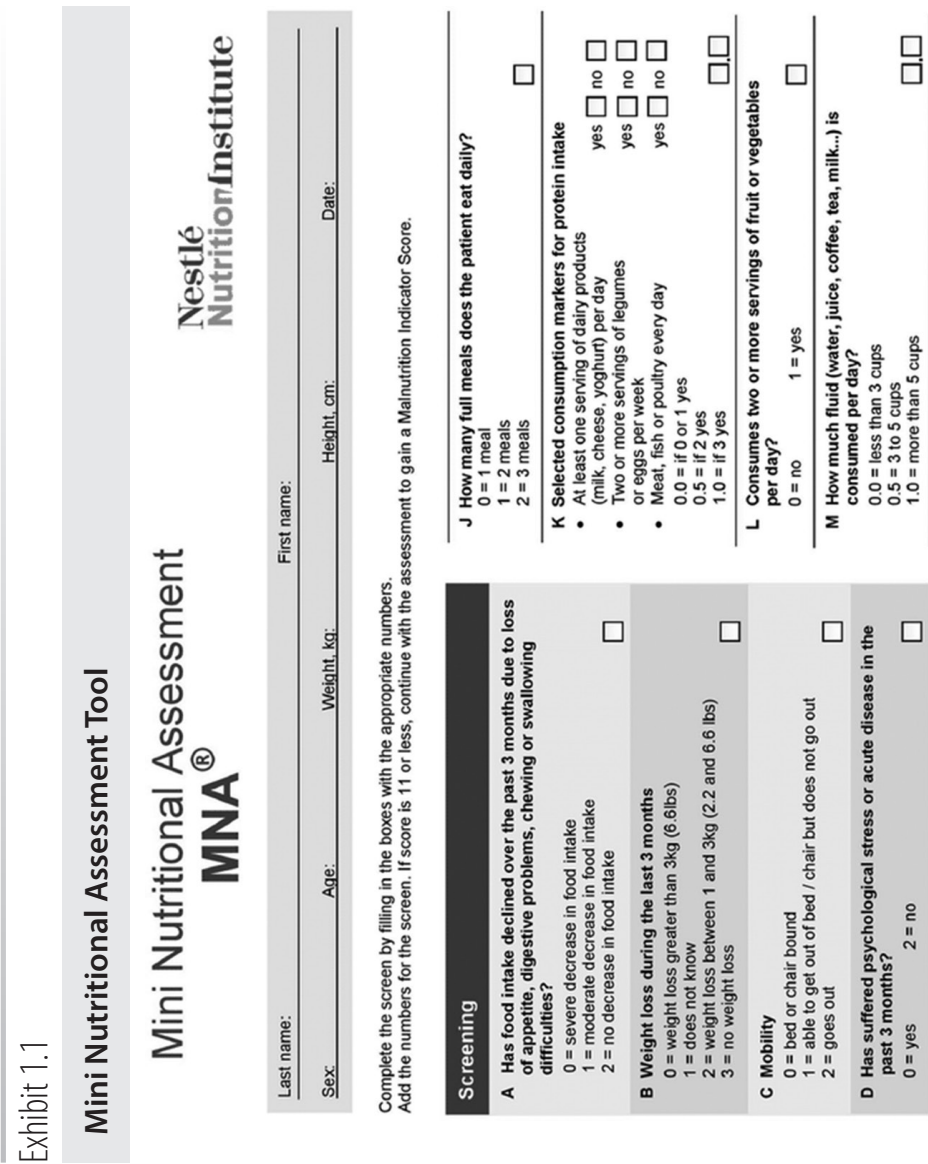

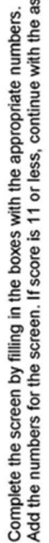

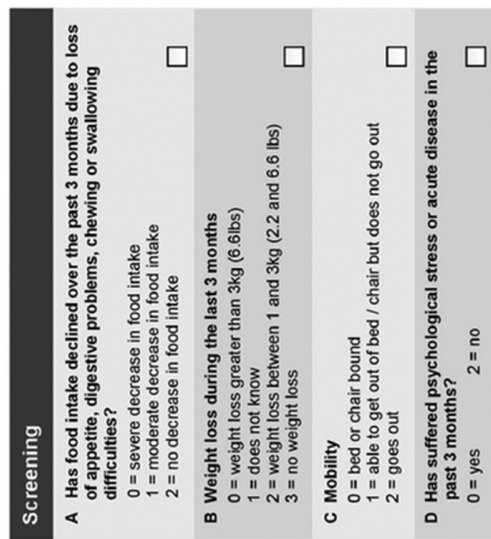




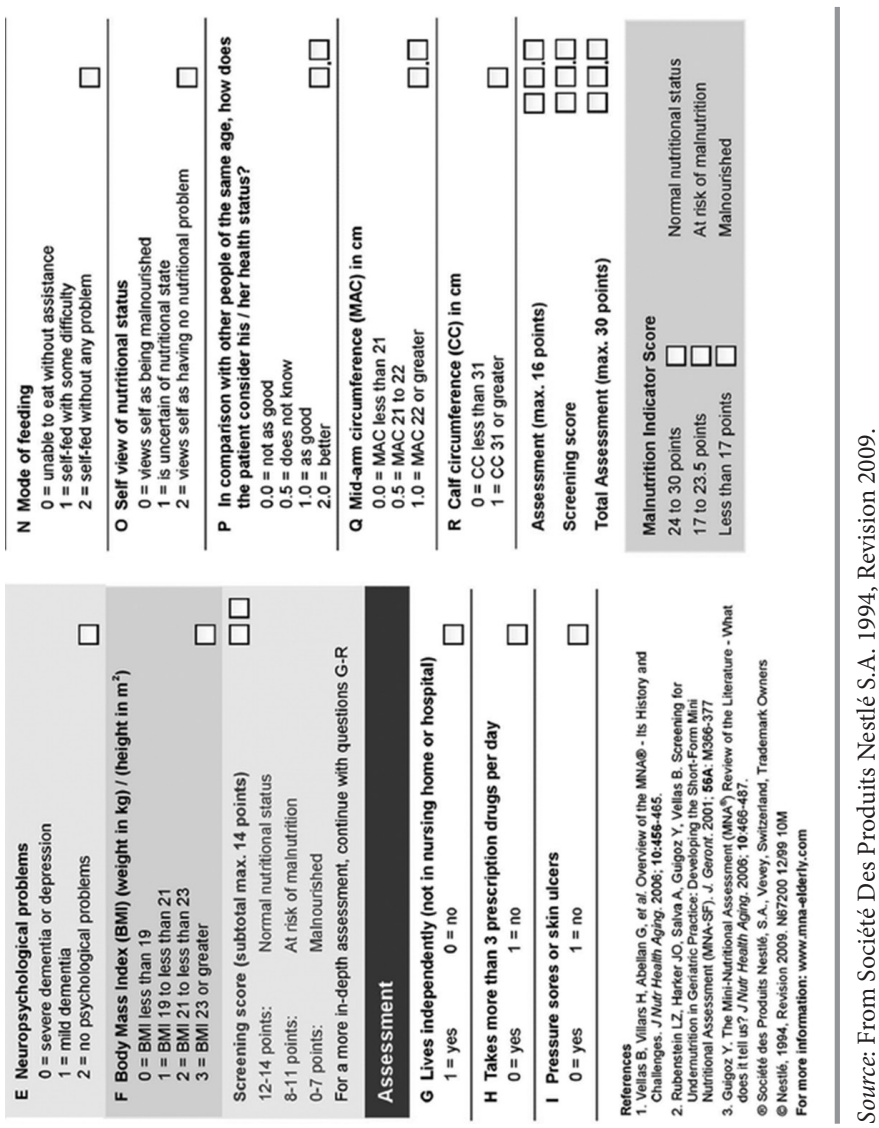

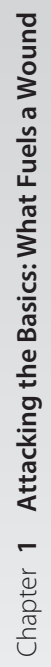




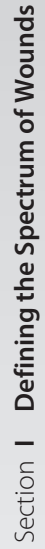

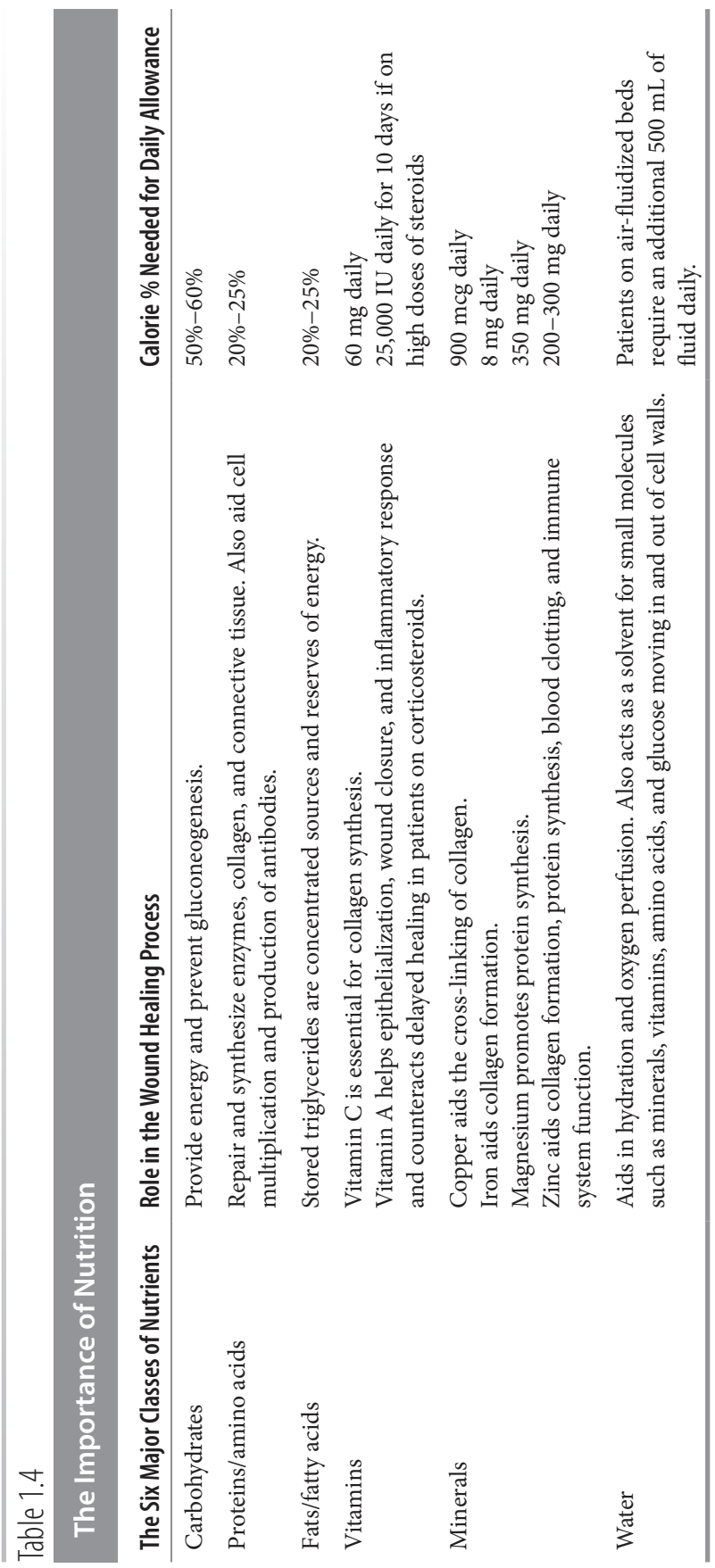




\section{Educator: Empowering Staff by Teaching}

- Is able and willing to train students and new providers and to offer novice staff wound care support.

- Develops a program for organizing wound and skin care products.

- Teaches the program and products to the wound care team and staff.

- Understands that wound care can be intimidating, continually changing, and frustrating to staff. The wound care provider is the resource for problem-solving, the sounding board, and the wound care escalation point person.

\section{Researcher: Improving Quality, Making Evaluations, and Collecting Data}

- Understands the scope of studies and appraises quality improvement.

- Understands and develops clinical markers for treatment options and guidelines-from aggressive wound care to palliative care.

- Observes the wound team members and helps develop novice team members to consultancy experts or providers who can empower others.

Even the best wound care providers will experience a less-thandesired outcome for their patients if the caretakers are unwilling or unable to implement the treatment plan effectively. The wound care provider and team must carefully assess who will be the patients' primary care providers and ensure ongoing education and handson instruction pertaining to wound care, dressing changes, pressure redistribution, incontinence management, nutrition, and so forth.

In this case, enlist the assistance from community resources such as home health to include skilled nurses and aides, physical and occupational therapists, and respite or hospice services as needed. If the patient will be placed in an acute care facility or long-term skilled nursing facility, determine if the facility has the resources necessary to treat a patient with a complex wound.

When considering a new facility, consider the following:

- Does the facility have a dedicated wound care nurse or team?

- Can they get the wound care supplies necessary to manage the wound appropriately?

- Can they provide regular follow-up with the wound care health provider? 


\section{MAJOR COMPONENT 3: TYPE OF DRESSING}

Wound care dressings can be complex, so make good choices for each individual wound. Wound care specialists must stay abreast of manufacturers and the latest technologies in wound care offerings. Get to know your wound care representatives. Ask for samples, open the products, and examine them and compare them with others in the same category. Ask questions to determine what characteristics of individual products make them preferable and find out how they will benefit your patients' wounds. Patients and their care providers can also provide invaluable information regarding types of wound dressings and products, so ask questions with every visit. Important information to gather includes ease of use and administration, comfort/pain, and affordability. Selecting the correct dressings and the types of dressings will be discussed at length in Chapter 9.

\section{Fast Facts}

Question: How do you know that a wound care product is what it claims to be?

Answer: The U.S. FDA establishes and monitors the quality of dressings and products and addresses violations from manufacturers, which is detailed on $510(\mathrm{k})$ forms. Wound care providers should determine if the products they are using are FDA approved.

\section{Bibliography}

Kadam, S., Shai, S., Shahane, A., \& Kaushik, K. (2019, April 30). Recent advances in non-conventional antimicrobial approaches for chronic wound biofilms: Have we found the "chink in the armor"? Biomedicines, 7(2), 2-13. Retrieved from https://www.ncbi.nlm.nih.gov

Nestle HealthScience Mini Nutritional Assessment. Retrieved from www .mna-elderly.com

Quain, A., \& Khardori, N. (2015, December). Nutrition in wound care management: A comprehensive overview. Wounds, 27(12), 2-4. Retrieved from https://www.ncbi.nlm.nih.gov

Rehm, K. (2015, December). Exploring options for certification in wound care. 9(9), 2. Retrieved from https://www.TodaysWoundClinic.com 